\title{
Retrospective analysis of the role and performance of family medicine versus emergency medical services in the pre- hospital management of patients with AMI in Banja Luka
}

\author{
${ }^{1}$ Department for family medicine \\ Primary Health Center Banja Luka \\ ${ }^{2}$ University of East Sarajevo, Faculty of \\ Medicine Foča, Bosnia and Herzegovina \\ ${ }^{3}$ School of Medicine, University of Banja \\ Luka, Bosnia and Herzegovina
}

Biljana Lakić ${ }^{* 1}$, Maja Račić 2 , Duško Vulić ${ }^{3}$

\footnotetext{
${ }^{*}$ Corresponding author: biljanakd@yahoo.com Tel.: + 38751215447

Fax.: + 38758210420
}

Received: 26 August 2015

Accepted: 9 March 2016

Key words: Acute myocardial infarction - Family medicine - Emergency medical services.

\begin{abstract}
Objective. The aim of this study was to investigate the differences in pre-hospital care of patients with acute myocardial infarction between emergency medical services and family medicine. Patients and methods. This retrospective descriptive study included patients treated for acute myocardial infarction at the University Clinical Centre of Banja Luka, in the period from 1st January to 31st December 2011. The patients were divided into two groups: patients who received a hospital referral from the family medicine service and those who received one from the emergency medical service. Results. The majority of patients (54.8\%) received pre-hospital care from emergency medical services, while in $24.8 \%$ of cases the care was provided by family medicine physicians. The analysis showed that the time that passed from the onset of symptoms to the visit to the health institution of first medical contact was shorter in the emergency medical service $(p<0.001)$. The average time from the onset of symptoms to arrival at the family practice was 24 hours, and to the emergency service 2 hours. The patients who established their first medical contact with the emergency service reported more severe symptoms than the ones who visited a family practice over the same period of time. Conclusion. The severity of symptoms affected the patients' decisions to seek help in a timely manner and to choose the facility of first medical contact. Interventions to decrease delay must focus on improving public awareness of acute myocardial infarction symptoms and increasing their knowledge of the benefits of early medical contact and treatment. Continuing education of family practitioners in this field is required.
\end{abstract}

\section{Introduction}

Acute myocardial infarction (AMI) is, according to the electrocardiographic changes, divided into two types, and, alongside unstable angina pectoris, represents one aspect of acute coronary syndrome (ACS), as defined in the special guidebooks $(1,2)$ used for rapid disease risk assessment and pertinent treatment. New findings confirm that AMI may be defined on the basis of different aspects based on clinical, electrocardiographic, biochemical and pathological characteristics, which are all presented in the new universal definition of AMI (3).

Every year over 17 million people in the world die from cardiovascular disease (CVD). AMI alone affects over 6 million people worldwide, while approximately $25 \%$ case result in mortality. It has been predicted 
that by 2020, CVD will be responsible for the majority of lethal outcomes in both developed and developing countries (4-6). In the Republika Srpska (RS), according to data provided by the Republic's Statistics Agency, during the past two decades, from 1998 to 2010, mortality ranged between $47.5 \%$ and $54.5 \%$. According to the Public Health Institute of the RS, in 1999 outpatient morbidity was $8.4 \%, 13 \%$ in hospitals, while the morbidity rate among the population aged 18-65 years amounted to $15.6 \%(7)$.

With the reform of health care, the family medicine model in the RS extended the scope of services delivered in the primary health setting by family practitioners and family medicine nurses to include health education, and disease prevention interventions, and expanded diagnostic and curative services, thus enabling the family medicine team to act as a gate keeper while providing more comprehensive and continuous health care services to its registered population. One family medicine team (consisting of one family practitioner and two nurses) provides primary care for 2000 inhabitants (8). The actual visit length for patients and physicians is approximately 10 minutes. Depending on the number of teams, the number of inhabitants, population density and the risk of injuries and acute illness, emergency care could be organized as: a "standby" service in the primary care centers, employing less than 5 family medicine teams $(<10,000$ inhabitants); a "duty" service in the towns with populations between 10,000 and 40,000 and as an "emergency service" in the health centers providing primary care for more than 75,000 inhabitants and able to employ 5 or more teams (a physician with specialization in emergency medicine or family medicine, two nurses and a driver) working in shifts (one team per 12,000 in towns of up to 80,000 inhabitants, and one team more for every further 20,000 inhabitants). It is estimated that the total population of the RS is
$1,200,000$. Care is provided by 54 primary care centers and 11 hospitals.

There are different approaches to the management of patients with suspected AMI around the world. Patients with chest pain are initially seen by their family practitioner (9). Due to the fear of possible consequences of AMI for heart function, primary health care providers tend to refer the majority of patients with symptoms of chest pain to a hospital, so national health systems in different countries are trying to make strategies for improving the diagnosis and treatment of patients with chest pain caused by AMI at the level of family medicine, especially in places where no emergency service is available (10-13).

The accuracy of family practitioners' diagnoses and pre-hospital treatment of AMI is not easily studied. It is necessary to find out not only how often AMI is diagnosed correctly but also how often this diagnosis is missed. Frequently, family practitioners base their diagnoses to an unjustifiable extent on the presence or absence of particular symptoms which are thought to be specific for AMI. On the other hand, the diagnostic accuracy of a family practitioner who does not have the support of diagnostic aids, such as laboratory biomarkers, would be expected to be less distinctive in comparison to the emergency medical service. The role of family practitioners should include responding quickly to patients with chest pain, giving adequate analgesia, aspirin, initiating treatment of complications and introducing antithrombolitic therapy (14).

In order to secure the resources for the greatest possible improvement in pre-hospital diagnoses and treatment of patients with myocardial infarction, in 2009 the Ministry of Health of the RS, published clinical guidelines for primary health care: "Acute myocardial infarction". The guidelines were distributed in printed and electronic form to all family practitioners registered in the 
$\mathrm{MoH}$ base. However, no impact evaluation has been conducted since then and the degree of change in pre-hospital diagnoses and treatment delivered by family practitioners remains unknown (15).

The aim of this study was to investigate the differences in pre-hospital diagnoses and treatment for patients with acute myocardial infarction between the emergency medical services and family medicine. We hypothesized that emergency medical services provide more accurate diagnosis and treatment to patients before hospitalization in an acute coronary unit.

\section{Patients and methods}

A retrospective descriptive study included patients treated for acute myocardial infarction at the University Clinical Centre of Banja Luka, in the period from 1st January to 31st December, 2011. The first inclusion criterion was that the patients were resident in Banja Luka or Laktaši. The second was written consent obtained from patients for participation in the research.

The population of the town of Banja Luka is 240,000 . Emergency services are provided by a separate unit which provides 24 -hour emergency care and several teams working within one shift. The nearest hospital is a few kilometers away. The population of the town of Laktaši is 31,000. Emergency cases are handled by all family practitioners until $3 \mathrm{pm}$ and from that time until $7 \mathrm{am}$ the next day by a single team. The nearest hospital is 30 kilometers away. In respect to the location of these two towns, the parameters of the pre-hospital care provided were compared.

The patients who had positive laboratory markers for myocardial necrosis (e.g., troponin I), along with supportive evidence in the form of typical symptoms, suggestive electrocardiographic (ECG) changes, or imaging evidence of new loss of viable myocardium or new regional wall motion abnormality, were diagnosed as having AMI at the University Clinical Centre of Banja Luka. The list of the patients with AMI was obtained from the administrative office of the University Clinical Centre of Banja Luka. The National Insurance Company provided a list and contact details of family practices who were involved in the pre-hospital care of patients.

The patients were divided into two groups: patients with AMI who received a hospital referral from their family medicine service (FMS) and those who received one from the emergency medical services (EMS). Data were extracted from the patient's medical history and discharge letters, as well as from

Table 1 The analyzed parameters

\begin{tabular}{|c|c|}
\hline \multicolumn{2}{|l|}{ Parameters } \\
\hline Location of pre-hospital care & FMS or EMS \\
\hline Chest pain & Present or absent \\
\hline Associated symptoms & Shortness of breath; Nausea and vomiting; Sweating; Other \\
\hline The circumstances of the occurrence of symptoms & At home/rest/work/during physical activity \\
\hline The time of the occurrence of symptoms & Morning/afternoon/evening/night \\
\hline $\begin{array}{l}\text { The time that passed from the occurrence of pain to } \\
\text { the health center visit }\end{array}$ & Minutes/Hours \\
\hline ECG changes & STEMI/NSTEMI \\
\hline Referral diagnosis & AMI/angina pectoris/other \\
\hline Pre-hospital treatment received & Oxygen; Analgesics; Nitroglycerin; Aspirin \\
\hline
\end{tabular}

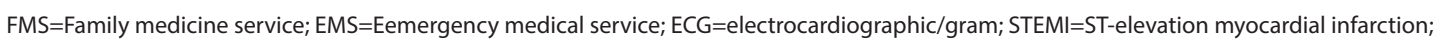
NSTEMI= non-ST-elevation myocardial infarction. 
their electronic and paper records, to analyze the parameters of pre-hospital care. All aspects of the medical records were included in the search for evidence of the quality of the pre-hospital care provided, such as free text. The entire paper record from the date of diagnosis was also included. The protocols at the Primary Care Centers were analyzed, and then telephone interviews were carried out by the researchers.

According to the national clinical guidelines for primary care, the diagnostic criteria for AMI are defined as: the presence of the typical chest pain, evolutionary changes in consecutive ECGs and evolutive changes in cardiac biomarkers. For each patient, the parameters of pre-hospital care were analyzed as shown in Table 1.

\section{Ethics statement}

The study was conducted in accordance with the 1975 World Medical Association Declaration of Helsinki and its amendments from 1983. The study was approved by the Committee of the Medical Faculty of the University of Banja Luka (18-3-27/2015).

\section{Statistical analysis}

The data were analyzed and are presented using descriptive statistics and the appropriate statistical methods ( $\chi 2$ test, MannWhitney, Fisher test) and SPSS statistical software. A probability level or $p$ value less than $0.05(p<0.05)$ was considered statistically significant.

\section{Results}

During 2011, 516 patients were treated at the University Clinical Centre of Banja Luka for AMI. Of those, 173 were excluded from the study because they did not meet the inclusion criteria. The study included 343 patients with residence in Banja Luka or Laktaši.
The average age of the patients was $66 \pm 11$ years and $63.8 \%$ were male. Out of 343 patients, 270 had recorded data on pre-hospital care. The majority of patients (54.8\%) received care through emergency medical services, while in $24.8 \%$ of cases pre-hospital care was provided by a family medicine service (Table 2). In $83.5 \%$ of patients the pain and/or other symptoms started at home, with onset mainly while resting (59.5\%).

As shown in Figure 1, 48\% of patients reported that their symptoms first started during the morning hours. Chest pain was the most predominant symptom in both genders and all age groups. However, female patients older than 75 years of age reported pain less often as the most predominant symptom compared to the male patients of the same age ( $\mathrm{p}=0.014)$ (Table 3$)$.

No significant difference in the frequency of associated symptoms between the patients referred from FMS and EMS was found ( $>0.05$ ) (Figure 2).

The analysis showed that the time that passed from the onset of symptoms to the visit to the health institution of first medical contact was shorter in patients receiving pre-hospital care from an EMS $(\mathrm{p}<0.001)$. The average time from onset of symptoms until arrival at the FMS was 24 hours and at the EMS 2 hours. The patients who used the services of EMS reported more severe symptoms than those who visited their FMS over the same period of time $(\mathrm{p}<0.001)$. During

Table 2 Distribution of patients according to the first medical contact

\begin{tabular}{ll}
\hline First medical contact & $\mathrm{n}(\%)$ \\
\hline Family medicine & $85(24.8)$ \\
Emergency medical service & $188(54.8)$ \\
Other* & $53(15.4)$ \\
Unknown & $17(5.0)$ \\
\hline *Direct hospitalization without pre-hospital care, being referred \\
from a private medical institution, intra-hospital transfer, patients \\
who suffered acute myocardial infarction in different cities, outside \\
of their place of residence.
\end{tabular}


Acta Medica Academica 2016;45:10-18

Table 3 The presence of pain as the predominant symptom according to age and gender

\begin{tabular}{|c|c|c|c|c|c|}
\hline \multirow{2}{*}{\multicolumn{2}{|c|}{ Age and gender groups }} & \multicolumn{2}{|c|}{ Chest pain } & \multirow{3}{*}{$\begin{array}{l}\text { Total } \\
11\end{array}$} & \multirow{2}{*}{$p$} \\
\hline & & \multirow{2}{*}{$\begin{array}{l}\text { Present } \\
11\end{array}$} & \multirow{2}{*}{$\begin{array}{l}\text { Absent } \\
0\end{array}$} & & \\
\hline \multirow{3}{*}{$\leq 54$} & Female & & & & \multirow{3}{*}{$0.565^{*-*}$} \\
\hline & Male & 36 & 4 & 40 & \\
\hline & Total & 47 & 4 & 51 & \\
\hline \multirow{3}{*}{$55-64$} & Female & 17 & 2 & 19 & \multirow{3}{*}{$1.000^{* *}$} \\
\hline & Male & 46 & 7 & 53 & \\
\hline & Total & 63 & 9 & 72 & \\
\hline \multirow{3}{*}{$65-74$} & Female & 28 & 2 & 30 & \multirow{3}{*}{$1.000^{*-}$} \\
\hline & Male & 44 & 4 & 48 & \\
\hline & Total & 72 & 6 & 78 & \\
\hline \multirow{3}{*}{$\geq 75$} & Female & 27 & 9 & 36 & \multirow{3}{*}{$0.014^{*-*}$} \\
\hline & Male & 32 & 1 & 33 & \\
\hline & Total & 59 & 10 & 69 & \\
\hline \multirow{3}{*}{ Total } & Female & 83 & 13 & 96 & \multirow{3}{*}{$0.369^{*}$} \\
\hline & Male & 158 & 16 & 174 & \\
\hline & Total & 241 & 29 & 270 & \\
\hline
\end{tabular}

${ }^{*} \chi 2$ test with Yates correction; ${ }^{* *}$ Fisher test; $p$ value $<0.05$ is considered significant.

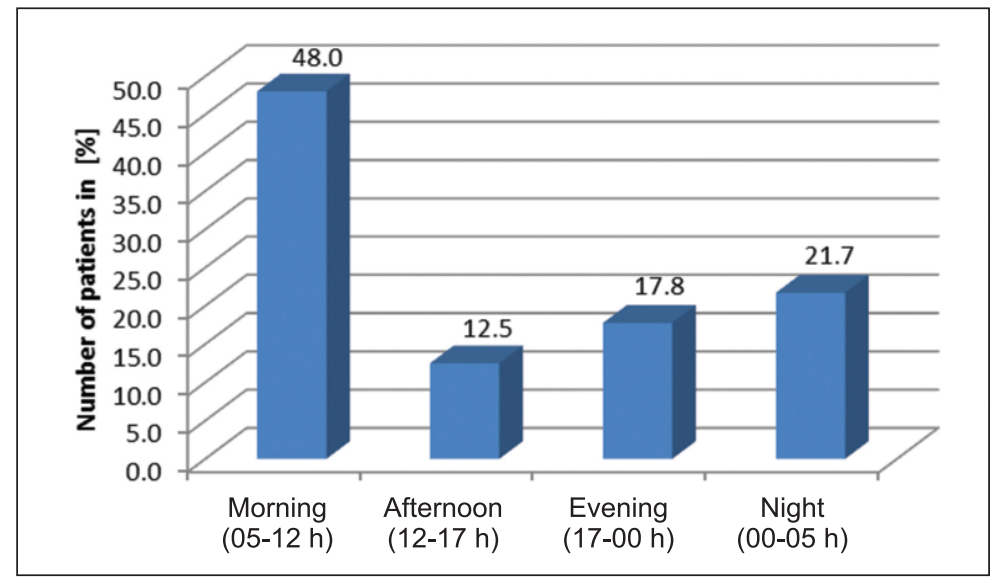

Figure 1 The onset of the AMI symptoms according to the time of the day.

the telephone interviews, the patients who received pre-hospital care in an EMS reported that they chose the EMS as the first point of care $(89.3 \%)$ because it was easier to access it either by phone or by a personal visit. On the other hand, $92 \%$ of patients referred from the FMS preferred to have the first contact with their family practitioner.

AMI, as the referral diagnosis, was more often confirmed in patients referred from the EMS (52\%) to the University Clinical Centre of Banja Luka than in the patients referred from a family medicine service (33\%). This difference was statistically significant ( $\mathrm{p}=0.013)$ as shown in Table 4.

However, the referral diagnoses in FMS were made on the basis of ECG findings and clinical presentation, because cardiac biomarkers were not available (85 patients). On the basis of ECG changes, STEMI (ST- 


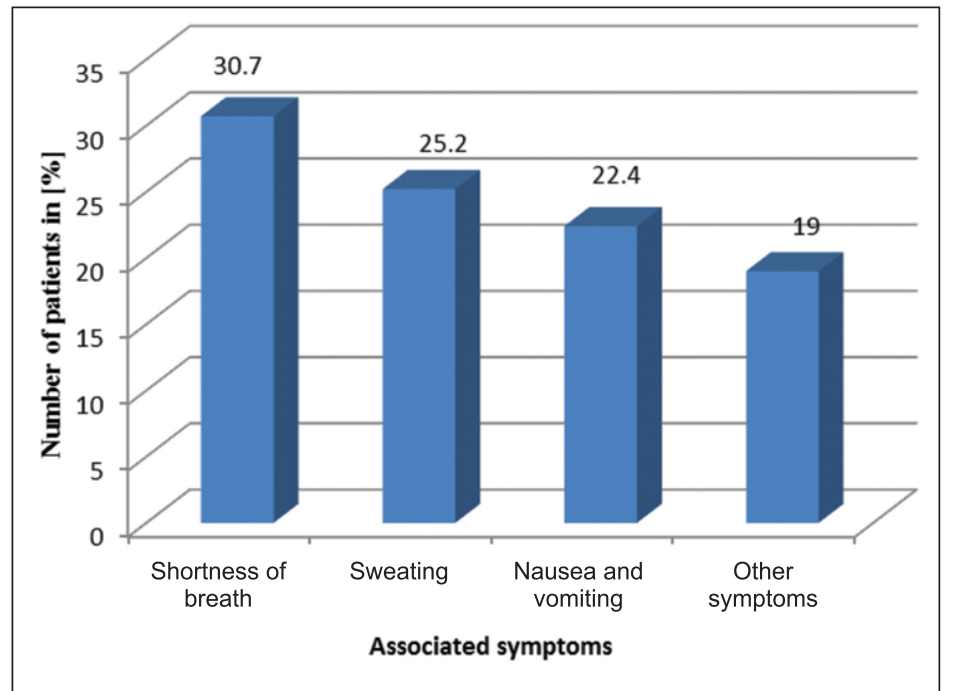

Figure 2 Associated symptoms in patients with acute myocardial infarction.

Table 4 Referral diagnoses according to the institution of first medical contact

\begin{tabular}{lll}
\hline \multirow{2}{*}{ Referral diagnosis } & The first medical contact & \\
\cline { 2 - 3 } & FMS (\%) & EMS (\%) \\
\hline Myocardial infarction & 33 & 52 \\
Angina pectoris & 51 & 34 \\
Other & 16 & 14 \\
\hline
\end{tabular}

FMS=Family medicine service; EMS=Emergency medical service; $X 2(2.247)=8.686, p=0.013$.

segment elevation myocardial infarction) occurred more often than NSTEMI (non ST-segment elevation myocardial infarction) $(54.8 \%$ vs. $44.7 \%)$, regardless of the institution where the first medical contact was made.

Pre-hospital antithrombotic therapy (aspirin) was employed equally in both institutions, without any statistical significance $(p=0.057)$. From the analysis of the use of the remaining pre-hospital therapies (oxygen, nitroglycerin and analgesics), a statistically significant difference was found between empirical treatment in the FMS and the EMS $(\mathrm{p}=0.002$; vs. $\mathrm{p}=0.006$; vs. $\mathrm{p}=0.001)$. From the analysis of the pre-hospital treatment approach, it was shown that cardiopulmonary resuscitation (CPR) was performed in $7(2 \%)$ patients with AMI, mainly in the EMS (1.7\% vs. $0.3 \%$ ), while anti-shock therapy (adrenalin) was used in $3(0.9 \%)$ patients.

\section{Discussion}

In this study it has been shown that patients with AMI are twice as likely to seek the first medical contact in an emergency service than from their family practitioner. The results are in accordance with the results of different studies showing that a minority of patients with cardiogenic chest pain seek help from a family practitioner, while in the majority of cases help is sought in an EMS (16-18). Patients referred from the EMS reported more severe chest pain compared with FMS patients. This could possibly explain why the majority of patients established their first medical contact in an EMS, as well as the shorter delay in seeking medical help and the greater accuracy in the diagnosis. However, the time frame for seeking medical help might also be related to a lack of information, not only to the severity 
of symptoms, concerning the significance of the pain, denial that the chest pain may actually signal a heart attack, misinterpretation of the chest pain, reluctance to call the family practitioners at an inconvenient time and lack of encouragement from family members for seeking medical help (19-22).

The definitive and referral diagnosis from the FMS coincided to a lesser degree with the diagnosis made in the EMS. A patient with myocardial infarction must be rated as one of the most serious emergency conditions family practitioners have to deal with. As the first doctors to see the patients, they are in very good position to make a proper diagnosis and apply the recommended therapy, which could save patients' lives, especially in rural areas where the nearest hospital is far away. The initial goal is to determine whether the patient needs to be referred for further testing to rule out an AMI (23). Differentiating ischemic from non-ischemic causes is often difficult, and patients with chest pain of ischemic etiology often appear to be well.

In FMS, the physicians only used an electrocardiogram to confirm the diagnosis. On the basis of the results of this study it may be said that in family practice acute myocardial infarction cannot be diagnosed with satisfactory accuracy on the basis of symptoms and electrocardiogram findings alone. Laboratory biomarkers could solve the diagnostic dilemma of the family physician, but they often lacking in primary care, although the majority of FMS in the RS were supplied with adequate laboratory apparatus by the Ministry of Health of the RS several years ago. Easier access to biomarkers could enable the physician to diagnose and treat AMI, or to exclude this condition if its presence is suspected, thereby reassuring both the physician and the patient (24-26). The problem of supplying the FMS in Banja Luka with the chemicals for determining biomarker needs to be addressed at the level of the national insurance company.

Besides being better equipped for diagnosing AMI, an EMS is oriented toward emergency care, rather than delivering and coordinating comprehensive care for patients. In Bosnia and Herzegovina, family physicians look after 1500-2000 registered patients. Their daily schedule is very busy and includes seeing approximately 50 or more patients a day. Public and health expectations, their paper workload as well as the constantly changing administrative regulations contribute to the perception of an increased level of pressure. This pressure often negatively affects the family physician's work-productivity, and thus potentially compromises not just the quality of care but also patient safety. Accordingly, family physicians with a higher proportion of patient visits and a higher numbers of patients are more likely to miss diagnoses of emergencies than EMS physicians. The false negative diagnoses of AMI made by the family practitioner represented a significant proportion of cases, which shows that the diagnostic accuracy of primary care practitioners should be improved, through continuing medical education and better equipment. It is also very important to improve education in the field of emergency medicine during undergraduate studies and residency in family medicine at all five medical schools in Bosnia and Herzegovina.

Some important differences between the management practices of family practitioners and EMS physicians emerged. Aspirin was commonly used in the FMS as well as in the EMS. However, EMS physicians were significantly more likely to use analgesics, oxygen and thrombolytic therapy. Family physicians, especially working in an urban environment, prefer to refer the patients to the hospital than to give thrombolytic therapy to the patients themselves. One British study conducted in primary health care 
(27) showed that general practitioners more seldom decide to use thrombolytic therapy (1\%), despite good knowledge and available guidelines, due to the fear of bleeding. Further research on the influences of family practitioners' management choices would be valuable and could help guide educational responses.

The present study showed discrepancies between the guideline recommendations and clinical practice, indicating the need for quality improvement of pre-hospital diagnostic and therapeutic approaches to AIM patients in the primary care centers in Banja Luka and Laktaši. The recent study from the United Kingdom showed that implementing a Quality Improvement Collaborative could be very successful in the context of pre-hospital urgent care through engagement of staff in the use of quality improvement methods and by providing individual feedback to frontline clinicians (28).

The study does, however, have some limitations. This was a retrospective study so it could only identify potential associations. Larger and more longitudinal data are needed to provide an assessment of quality indicators and outcomes of pre-hospital care.

\section{Conclusion}

Emergency medical services provide a more accurate diagnosis and treatment approach to patients with AMI before hospitalization in an acute coronary unit compared to family medicine services. Top priority in primary care should be given to patients with chest pain in whom acute myocardial infarction is suspected. The severity of symptoms affects the patient's decision to seek help in a timely manner and to choose the facility of first medical contact. Continuing education of family practitioners in the field of acute myocardial infarction is required. Physicians should consider applying a validated clinical decision rule to predict coro- nary heart disease as a cause of chest pain. Interventions to decrease delay must focus on improving public awareness of the symptoms of acute myocardial infarction and increasing their knowledge of early response and treatment benefits.

\section{What is already known on this topic}

In most patients with acute myocardial infarction, the dominant symptom is chest pain that occurs mainly in the morning. Patients with symptoms of acute myocardial infarction seek help predominantly from an emergency medical service.

What this study adds

The severity of symptoms affects the patient's decision to seek help in a timely manner and to choose the facility of first medical contact. This study has shown that patients with acute myocardial infarction are twice as likely to seek help from an emergency medical service than from a family medicine surgery. Emergency medical services provide more accurate diagnosis and treatment to patients with AMI. This study gives recommendations for improving the work of all health care services responsible for the pre-hospital care of patients with acute myocardial infarction.

Authors' contributions: Conception and design: BL; Acquisition, analysis and interpretation of data: $\mathrm{BL}$ and MR; Drafting the article: BL; Revising it critically for important intellectual content: $\mathrm{BL}, \mathrm{MR}$ and $\mathrm{DV}$; Approved final version of the manuscript: BL, MR, and DV.

Conflict of interest: The authors declare that they have no conflict of interest.

\section{References}

1. Van de Werf F, Bax J, Betriu A, Blomstrom-Lundqvist C, Crea F, Falk V, et al. Management of acute myocardial infarction in patients presenting with persistent ST-segment elevation: the Task Force on the Management of ST-Segment Elevation Acute Myocardial Infarction of the European Society of Cardiology. Eur Heart J. 2008;29(23):2909-45.

2. Hamm CW, Bassand JP, Agewall S, Bax J, Boersma E, Bueno $\mathrm{H}$, et al. ESC Guidelines for the management of acute coronary syndromes in patients presenting without persistent ST-segment elevation: The Task Force for the management of acute coronary syndromes (ACS) in patients presenting without persistent ST-segment elevation of the European Society of Cardiology (ESC). Eur Heart J. 2011;32(23):2999-3054. 
3. Thygesen K, Alpert JS, Jaffe AS, Simoons ML, Chaitman BR, White HD, et al. Third universal definition of myocardial infarction. Circulation. 2012;126(16):2020-35.

4. World Health Organization. The global burden of disease: 2004 update. Geneva: WHO; 2008.

5. Fuster V, Kelly BB. Promoting Cardiovascular Health in the Developing World: A Critical Challenge to Achieve Global Health. Institute of Medicine (US) Committee on Preventing the Global Epidemic of Cardiovascular Disease: Meeting the Challenges in Developing Countries. Washington (DC): National Academies Press (US); 2010.

6. Mathers CD, Boerma T, Ma Fat D. Global and regional causes of death. Br Med Bull. 2009;92(1):732.

7. Vulić D, Krneta M, Šobot M. Guidelines for secondary prevention of coronary heart disease [in Serbian]. Srce i krvni sudovi. 2011;30(4):241-5.

8. Račić M. Family Medicine in Republic of Srpska. Opšta medicina. 2015;21(3-4):75-80.

9. Haasenritter J, Biroga T, Keunecke C, Becker A, Donner-Banzhoff N, Dornieden K, et al. Causes of chest pain in primary care - a systematic review and meta-analysis. Croat Med J. 2015;56(5):42230 .

10. Willemsen RTA, Buntinx F, Winkens B, Glatz JF, Dinant GJ, The 'RAPIDA'-study team. The value of signs, symptoms and plasma heart-type fatty acidbinding protein (H-FABP) in evaluating patients presenting with symptoms possibly matching acute coronary syndrome: background and methods of a diagnostic study in primary care. BMC Fam Pract. 2014;15:203.

11. British Heart Foundation working group. Role of the general practitioner in managing patients with myocardial infarction: impact of thrombolytic treatment. BMJ. 1989;299:555-7.

12. Burman RA, Zakariassen E, Hunskaar S. Management of chest pain: a prospective study from Norwegian out-of-hours primary care. BMC Fam Pract. 2014;15:51.

13. Krčmar N, Pristaš I, Stevanović R, Tonković A. The Role of the County's Health Centre in the Management of Patients with Acute Coronary Syndrome [in Croatian]. Hrvatski časopis za javno zdravstvo. 2010. [cited 2012 Mar 20]. Available from: http://www.hcjz.hr/old/clanak.php.

14. Murphy AW, McCafferty D, Dowling J, Bury G. One-year prospective study of cases of suspected acute myocardial infarction managed by urban and rural general practitioners. Br J Gen Pract. 1996;46(403):73-6.
15. Krneta M, Kuprešak D, Šatara-Stoisavljević S, Tepić R, Vulić D. Acute myocardial infarction: guidelines for Primary Health Care [in Serbian]. Banja Luka: Ministry of Health and Social Welfare of the Republic of Srpska; 2009.

16. Klinkman MS, Stevens D, Gorenflo DW. Episodes of care for chest pain. J Fam Pract. 1994;38(4):345-52.

17. Svavarsdóttir AE, Jónasson MR, Gudmundsson GH, Fjeldsted K. Chest pain in family practice. Diagnosis and long-term outcome in a community setting. Can Fam Physician. 1996;42:1122-8.

18. Miljuš D, Katalina Miskovski N. Incidence and Mortality of Acute Coronary Syndrome in Serbia. Belgrade: Institute of Public Health of Serbia "Dr Milan Jovanović Batut”; 2011.

19. Taghaddosi M, Dianati M, Bidgoli JFG. Bahonaran J. Delay and its Related Factors in Seeking Treatment in Patients with Acute Myocardial Infarction. ARYA Atheroscler. 2010;6(1):35-41.

20. Yu PN. Prehospital care of acute myocardial infarction. Circulation. 1972;45(1):189-204.

21. Ghazawy ER, Seedhom AE, Mahfouz EM. Predictors of Delay in Seeking Health Care among Myocardial Infarction Patients, Minia District, Egypt. Adv Prev Med. 2015;2015:342361.

22. Mussi FC, Mendes AS, de Queiroz TL, Costa AL, Pereira A, Caramelli B. Pre-hospital delay in acute myocardial infarction: judgement of symptoms and resistance to pain. Revista da Associação Médica Brasileira. 2014;60(1):63-9.

23. Bruyninckx R, Aertgeerts B, Bruyninckx P, Buntinx F. Signs and symptoms in diagnosing acute myocardial infarction and acute coronary syndrome: a diagnostic meta-analysis. Br J Gen Pract. 2008;58(547):105-11.

24. Kontos MC, Diercks DB, Kirk JD. Emergency department and office-based evaluation of patients with chest pain. Mayo Clin Proc. 2010;85(3):284-99.

25. McConaghy JR, Rupal O. Outpatient diagnosis of acute chest pain in adults. Am Fam Physician. 2013;87(3):177-82.

26. Cooper A, Timmis A, Skinner J; Guideline Development Group. Assessment of recent onset chest pain or discomfort of suspected cardiac origin: summary of NICE guidance. BMJ. 2010;340:c1118.

27. Round A, Marshall AJ. Survey of general practitioners' prehospital management of suspected acute myocardial infarction. BMJ. 1994;309(6951):375-6.

28. Siriwardena AN, Shaw D, Essam N, Togher FJ, Davy Y, Spaight A, et al. The effect of a national quality improvement collaborative on prehospital care for acute myocardial infarction and stroke in England. Implement Sci. 2014;9:17. 